\title{
Weight Category-dependent Trunk Muscle Strength and its Relation with LBP in Elite Judokas
}

\section{두)(i) (우)}

\author{
Authors \\ Takashi Okada1, Takayoshi Hakkaku², Kazunori Iwai ${ }^{3}$, Koichi Nakazato $^{4}$
}

\section{Affiliations}

1 Faculty of Sport Science, Nippon Sport Science University, Setagaya-ku, Japan

2 Department of Judo therapy, Japan Health and Medical College, Taito-ku, Japan

3 Department of Athletics (Wrestling),Western University, London, Canada

4 Graduate School of Health and Sport Science, Nippon Sport Science University, Setagaya-ku, Japan

Key words

athlete, martial art, weight category, injury, torso rotation

received 10.09 .2020

revised 29.10.2020

accepted after revision $\quad 03.11 .2020$

Bibliography

Sports Medicine International Open 2020; 4: E14-E21

DOI 10.1055/a-1303-2741

ISSN 2367-1890

(C) 2020. The Author(s).

This is an open access article published by Thieme under the terms of the Creative Commons Attribution-NonDerivative-NonCommercial-License, permitting copying and reproduction so long as the original work is given appropriate credit. Contents may not be used for commecial purposes, or adapted, remixed, transformed or built upon. (https://creativecommons.org/ licenses/by-nc-nd/4.0/)

Georg Thieme Verlag KG, Rüdigerstraße 14,

70469 Stuttgart, Germany

\author{
Correspondence \\ Takashi Okada \\ Faculty of Sport Science, Nippon Sport Science University, \\ 7-1-1 Fukasawa \\ 158-8508 Setagaya-ku \\ Japan \\ Tel : +81-3-5706-1024, Fax : +81-3-5706-1024 \\ t-okada@nittai.ac.jp
}

\section{ABSTRACT}

Trunk muscle strength (TMS), especially rotator, is an important factor for both athletic performance and injury risks in judokas. However, the characteristics of TMS that depend on weight categories are still unclear. Although inadequate TMS might cause low back pain (LBP), the relationship between these two variables is not fully understood. In this study, weight categorydependent TMS and its relationship with LBP was investigated in Japanese judokas. The subjects were 66 male collegiate judokas, who were classified into the lightweight $(N=14)$, middleweight $(\mathrm{N}=29)$ or heavyweight $(\mathrm{N}=23)$ category. The peak torques of extensor, flexor and rotator muscles were measured. The LBP group and non-LBP group were defined by questionnaire. TMS (normalized by body weight) in the heavier weight category showed a lower tendency in comparison with other categories, except for rotator strength. Significant differences were observed in the extensors (90 and $120 \%$ s; $\mathrm{P}<0.05)$ and flexors (60, 90 and $120 \%$; $P<0.05)$. The LBP group $(N=9)$ only showed significantly lower extensor $(60 \% \mathrm{~s} ; \mathrm{P}<0.05)$ and rightrotator $(60 \% \mathrm{~s} ; \mathrm{P}<0.01)$ strength in the heavyweight category compared with the non-LBP group $(\mathrm{N}=14)$. The relative TMS of judokas decreased in the heavyweight category, except for trunk rotator strength. Notably, low trunk extensor and rotator strengths are risk factors for LBP in heavyweight judokas.

\section{Introduction}

Judo is classified as a contact or combat sport. Seven weight categories (under $60,66,73,81,90,100$, and over $100 \mathrm{~kg}$ ) and/or the open-weight category is used in the current judo competitive regulation. In judokas, some researchers investigated muscle strength under various conditions across various regions (e. g., trunk, arm, knee, neck and shoulder) [1]. It has been shown that trunk muscle strength (TMS) is an essential element of judo, and more importantly, if TMS is weak in one area, imbalance may occur and the risk of injury increases [2].

In judo, it has also been reported that TMS is very important for athletic performance [2,3]. There is a strong possibility that the 
characteristics of one's TMS depend on his weight category because of the different loads on the lumbar region. However, no study has ever investigated the relationships between weight categories and TMS in judokas. For judo in particular, techniques involving trunk rotation and accentuated hip and knee flexion (e.g., seoi-nage) are more physically demanding than frontal attacks [4]. Also, judokas engage their trunk rotator strength to keep their posture stable for defense against their opponent's attack. However, there is no study investigating trunk rotator strength in judokas. The primary aim of this study is to investigate variations in TMS (flexion, extension, and rotation) in judokas across different weight categories.

Low back pain (LBP) is a frequent injury among athletes $[5,6]$, especially in judokas, wherein LBP has been reported to occur in 9.1-62.4\% [7]. We reported that ongoing LBP and anamnesis occurred in 35.7 and $64.3 \%$ of collegiate judokas, respectively [8]. There is no significant difference in the incidence of LBP by weight between the lightweight (34.5\%), middleweight (32.3\%), and heavyweight ( $40.9 \%$ ) category. Since such high incidences of LBP have been found among different types of athletes, it is very important that athletes and their coaches work toward its prevention. Although the pathogenesis of LBP is very complicated, the weakness of TMS is strongly implicated in contributing to LBP [9-13], but the relationship between these two variables remains an unresolved issue. Previous studies on ordinary people confirmed that those with LBP had lower TMS (extensor, flexor, and/or rotator) than those without LBP [14-16], but other studies did not draw the same conclusions $[17,18]$. In collegiate wrestlers, low TMS of the extensor muscles correlated to the functional disability level of LBP $[19,20]$. However, in judokas, there is no study regarding the relationship between LBP and TMS. Thus, the second aim of this study is to investigate the relationship between TMS and LBP in judokas.

We have already reported that LBP in the middle- and heavyweight categories tended to accompany lumbar radiological abnormalities; conversely, about half of the LBP cases (50\%) in the lightweight category were not accompanied by any lumbar radiological abnormalities [8], suggesting that body weight clearly had a mechanical impact on the lumbar region in judokas. In other words, stronger TMS is needed for heavyweight judokas. However, relative TMS normalized by body weight should be lower in heavyweight judokas because of their high body weight. Thus, we hypothesized that judokas in the heavyweight category show higher absolute TMS, but lower relative TMS normalized by body weight. Because of larger impact on the lumbar region for judokas in the heavyweight category, we also hypothesized the relationship between LBP and low TMS to be more evident in the heavyweight category.

\section{Material and Methods}

\section{Subjects}

Approval was obtained from the university's ethics committee and the study meets the ethical standards of this journal [21]. All the subjects gave written informed consent before participating. We informed all the subjects and their coaches of the purpose and po- tential risks of this study. The subjects were 66 male collegiate judokas. In this study, we classified judokas into three weight categories as follows; the lightweight category (under $60,66 \mathrm{~kg}$, $\mathrm{N}=14$ ), the middleweight category (under $73,81 \mathrm{~kg}, \mathrm{~N}=29$ ), and the heavyweight category (under 90,100 , over100 kg, $N=23$ ). The characteristics of the subjects are shown in $>$ Table 1 . All the subjects participated in judo practice for a total of 3 hours a day, with sessions happening twice a day, 6 days a week.

\section{Measurement of TMS}

TMS was measured isokinetically using the Biodex System 3 with the back attachment and the torso rotation attachment (Biodex Medical Systems, Inc., Shirley, NY, USA). The peak torques of trunk extensor (PTEX), flexor (RTFX), left-rotator (PTLR), and right-rotator (PTRR) muscles were measured at angular velocities of 60,90 , and $120 \%$ s. Two preliminary movements as practice were done before each measurement. Reciprocal movements such as extensionflexion and left rotation-right rotation were done 3 times for each velocity being tested, and 60 -second rest intervals were taken in between each velocity being tested. We employed TMS parameters such that the best value was normalized by dividing the subject's body weight with the PTEX, PTFX, PTLR, and the PTRR, respectively. Moreover, we calculated the extensor/flexor ratio (EX/ $\mathrm{FX}$ ) and the left-rotator/right-rotator ratio (LR/RR). For measurement of the extension-flexion cycle of the trunk, the subjects were placed in a semi-standing posture with their knees flexed at $15^{\circ}$. Trunk extension and flexion movements were performed along the frontal-horizontal axis that passed at the level of L5-S1. The range of motion of the movement was set at $90^{\circ}$. The chest, axillae, and dorsal surface of sacrum were fixed with straps and pads. For measurement of the left-right rotation cycle of the trunk, the subjects were placed in a sitting posture with their feet free above the floor. Trunk left-rotator and right-rotator movements were performed along the vertical axis that passed at the centriciput. The range of motion of the movement was set at $90^{\circ}$. The chest, axillae, bilateral surface of pelvis, and thighs were fixed with straps and pads.

\section{Evaluation of LBP}

The presence of LBP was evaluated by using the questionnaire test developed by Osaka City University (the OCU test) modified by Kuroki and Tajima [22]. The OCU test consisted of 10 questions about LBP-related activities of daily living: lying face up with an extended leg, rising from the bed in the morning, washing of the face in the morning, donning and removing trousers and socks while standing, using a Japanese-style toilet, sitting on a chair, standing, walking, going up and down the stairs, and lifting or holding heavy objects. The subjects graded each question according to the following criteria: possible without pain ( 0 points), possible with pain (1 point), impossible (2 points). Based on the test, we grouped the judokas into the non-LBP group and the LBP group when they scored 0 points and 1 or more points, respectively. In all the subjects, the non-LBP group and the LBP group had 43 and 23 subjects, respectively. In the lightweight category, there were 9 and 5 subjects, respectively. In the middleweight category, there were 20 and 9 subjects, respectively. Lastly, in the heavyweight category, there were 14 and 9 subjects, respectively. 


\section{Statistics}

We compared the parameters of TMS $(\mathrm{N} \cdot \mathrm{m}$ and $\mathrm{N} \cdot \mathrm{m} / \mathrm{kg})$ between 3 weight categories. A one-way analysis of variance (ANOVA) followed by a Bonferroni-Dunn post hoc test was used for statistical evaluation. We also compared the parameters of TMS $(\mathrm{N} \cdot \mathrm{m} / \mathrm{kg})$ between the non-LBP group and the LBP group within weight categories. Student's t-test was used for statistical evaluation. The level of significance was set at $5 \%$. All analyses were performed using IBM SPSS Statistics, version 25 (IBM Corp. Armonk, NY, USA). All experimental designs are shown in $>$ Fig. 1.

\section{Results}

\section{Comparison of the physical characteristics among different weight categories}

We first compared physical characteristics among different weight categories ( $\triangleright$ Table 1). There were significant differences in height, weight, and BMI, as expected. The heavyweight category showed significantly higher values than those of lighter weight categories.

\section{Comparison of TMS among different weight categories}

We have hypothesized that high absolute TMS would be observed in heavyweight judokas. The comparison of TMS among different weight categories is shown in $>$ Table 2 . As expected, absolute values of TMS were significantly higher in the heavyweight category than in lighter weight categories.

In the heavyweight category, relative flexion/extension TMS was significantly lower compared to the other two categories; namely, these low values were found for PTEX $90 \% \mathrm{~s}(\mathrm{p}<0.05)$ and $120 \% \mathrm{~s}(\mathrm{p}<0.05)$, and in PTFX $60 \% \mathrm{~s}(\mathrm{p}<0.005), 90^{\circ} \mathrm{s}(\mathrm{p}<0.01)$ and $120^{\circ} / \mathrm{s}(\mathrm{p}<0.001)$. Unexpectedly, significant differences were not observed in the relative rotator TMS.

\section{Comparison of TMS with regard to LBP}

We then investigated the physical characteristics of all subjects, both in the non-LBP and the LBP groups. As shown in $>$ Table $\mathbf{3}$, there are no significant differences of physical characteristics between the non-LBP and LBP groups regardless of weight categories.

- Table 1 Physical characteristics of 66 male collegiate judokas.

\begin{tabular}{|c|c|c|c|c|}
\hline & All subjects $(N=66)$ & Lightweight $(N=14)$ & Middleweight $(N=29)$ & Heavyweight $(\mathrm{N}=23)$ \\
\hline Age (years) & $20.2 \pm 0.9$ & $20.1 \pm 0.9$ & $19.9 \pm 0.8$ & $20.6 \pm 0.9$ \\
\hline Height (cm) & $172.7 \pm 6.3$ & $166.7 \pm 4.6$ & $172.9 \pm 5.3$ & $176.2 \pm 5.7$ \\
\hline Weight (kg) & $84.3 \pm 17.3$ & $66.0 \pm 4.3$ & $78.6 \pm 4.8$ & $102.6 \pm 15.5$ \\
\hline BMI $\left(\mathrm{kg} / \mathrm{m}^{2}\right)$ & $28.1 \pm 4.7$ & $23.7 \pm 1.0$ & $26.4 \pm 2.0$ & $33.0 \pm 4.3$ \\
\hline Judo history (years) & $10.9 \pm 3.0$ & $10.6 \pm 3.3$ & $10.4 \pm 2.8$ & $11.7 \pm 3.1$ \\
\hline
\end{tabular}

Data are presented as mean \pm SD. Lightweight, under $60 \mathrm{~kg}$ and $66 \mathrm{~kg}$ judokas. Middleweight, under $73 \mathrm{~kg}$ and $81 \mathrm{~kg}$ judokas. Heavyweight, under 90,100 , and over $100 \mathrm{~kg}$ judokas.

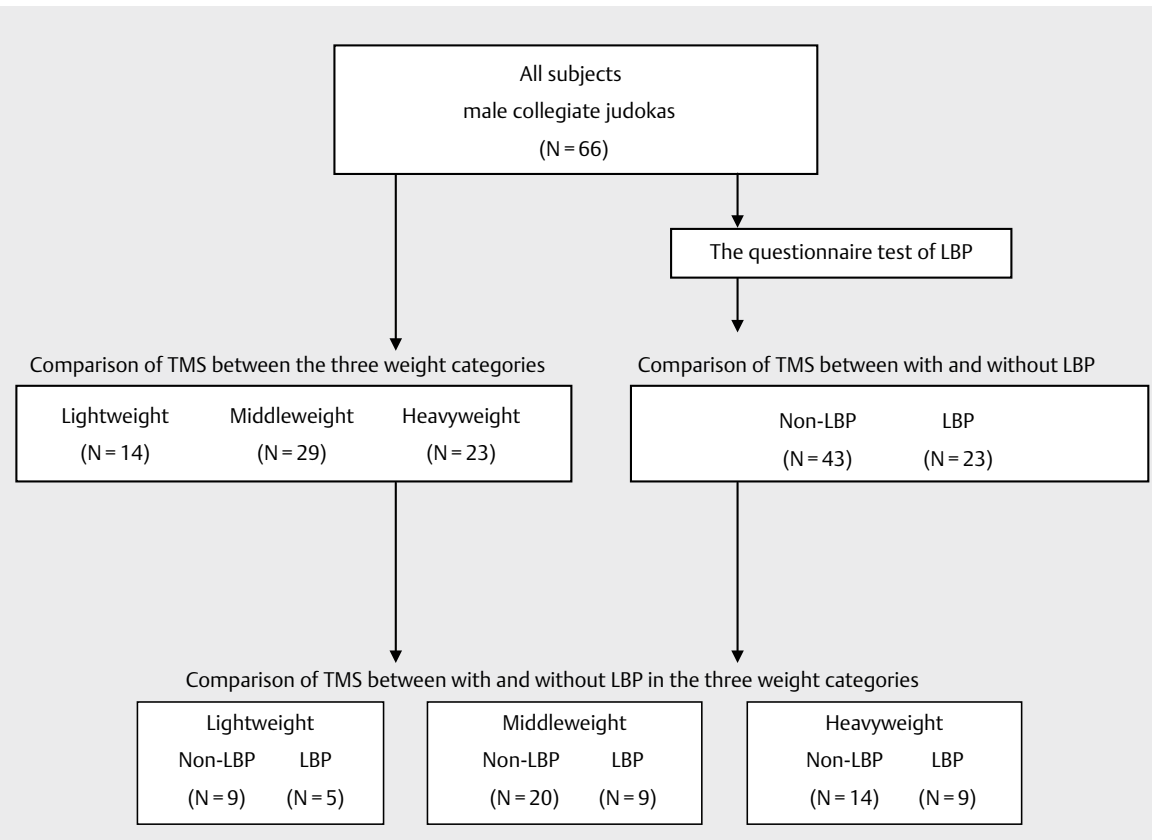

- Fig. 1 Experimental designs comparing trunk muscle strength (TMS). 
- Table 2 Comparison of peak torques of trunk muscles among weight categories. Values inside the parentheses show relative TMS normalized by body weight.

\begin{tabular}{|c|c|c|c|}
\hline Variables & Lightweight $(\mathrm{N}=14)$ & Middleweight $(\mathrm{N}=29)$ & Heavyweight $(\mathrm{N}=23)$ \\
\hline \multicolumn{4}{|c|}{ Extensor $(\mathrm{N} \cdot \mathrm{m})(\mathrm{N} \cdot \mathrm{m} / \mathrm{kg})$} \\
\hline $60 \% \mathrm{~s}$ & $447.4 \pm 106.3(6.7 \pm 1.3)$ & $508.8 \pm 75.6(6.5 \pm 1.0)$ & $609.5 \pm 92.7(6.0 \pm 0.7)$ \\
\hline $90 \% \mathrm{~s}$ & $439.3 \pm 83.1^{*}(6.6 \pm 1.0)$ & $496.5 \pm 58.7(6.3 \pm 0.8)$ & $597.8 \pm 95.8 *(5.8 \pm 0.7)$ \\
\hline $120 \% \mathrm{~s}$ & $421.9 \pm 81.6^{*}(6.4 \pm 1.0)$ & $481.2 \pm 68.9(6.1 \pm 0.8)$ & $575.8 \pm 107.4^{*}(5.6 \pm 0.8)$ \\
\hline \multicolumn{4}{|c|}{ Flexor $(\mathrm{N} \cdot \mathrm{m})(\mathrm{N} \cdot \mathrm{m} / \mathrm{kg})$} \\
\hline $60 \% \mathrm{~s}$ & $215.9 \pm 57.3(3.3 \pm 0.7)$ & $270.2 \pm 47.8 * *(3.4 \pm 0.6)$ & $290.7 \pm 75.4^{* *}(2.8 \pm 0.5)$ \\
\hline $90 \% \mathrm{~s}$ & $199.5 \pm 48.6(3.0 \pm 0.7)$ & $252.0 \pm 41.1 *(3.2 \pm 0.5)$ & $277.3 \pm 68.5^{*}(2.7 \pm 0.6)$ \\
\hline $120 \% \mathrm{~s}$ & $182.9 \pm 48.0(2.8 \pm 0.7)$ & $226.6 \pm 36.4 * *(2.9 \pm 0.4)$ & $239.9 \pm 55.2 * *(2.4 \pm 0.5)$ \\
\hline \multicolumn{4}{|c|}{ Left-rotator $(\mathrm{N} \cdot \mathrm{m})(\mathrm{N} \cdot \mathrm{m} / \mathrm{kg})$} \\
\hline $60 \% \mathrm{~s}$ & $150.8 \pm 18.5(2.4 \pm 0.3)$ & $177.9 \pm 23.1(2.4 \pm 0.3)$ & $218.1 \pm 34.6(2.1 \pm 0.2)$ \\
\hline $90 \% \mathrm{~s}$ & $148.5 \pm 22.8(2.3 \pm 0.2)$ & $173.8 \pm 23.7(2.2 \pm 0.3)$ & $212.5 \pm 33.7(2.1 \pm 0.3)$ \\
\hline $120 \% \mathrm{~s}$ & $144.8 \pm 19.6(2.2 \pm 0.2)$ & $170.3 \pm 19.8(2.2 \pm 0.2)$ & $206.3 \pm 32.1(2.0 \pm 0.3)$ \\
\hline \multicolumn{4}{|c|}{ Right-rotator $(\mathrm{N} \cdot \mathrm{m})(\mathrm{N} \cdot \mathrm{m} / \mathrm{kg})$} \\
\hline $60 \% \mathrm{~s}$ & $156.0 \pm 23.4(2.3 \pm 0.2)$ & $187.4 \pm 21.6(2.3 \pm 0.3)$ & $231.5 \pm 38.2(2.3 \pm 0.3)$ \\
\hline $90 \% \mathrm{~s}$ & $151.3 \pm 23.5(2.2 \pm 0.2)$ & $173.5 \pm 19.7(2.2 \pm 0.3)$ & $218.0 \pm 33.6(2.1 \pm 0.3)$ \\
\hline $120 \% \mathrm{~s}$ & $143.5 \pm 22.8(2.2 \pm 0.2)$ & $170.0 \pm 20.1(2.2 \pm 0.2)$ & $209.3 \pm 30.4(2.1 \pm 0.3)$ \\
\hline $\begin{array}{l}\text { Data are } p r \\
\text { heavyweigl } \\
(P<0.05)\end{array}$ & $\begin{array}{l}\text { own for relative values } \\
\text { ategories. }{ }^{*}: \text { Statistical } \\
\text { ved by Bonferroni-Dun }\end{array}$ & $\begin{array}{l}\text { the absolute values of TMS } \\
\text { th by ANOVA followed by BC } \\
\text { c test }(P<0.01) \text {. }\end{array}$ & $\begin{array}{l}\text { ificantly higher in the } \\
\text {-Dunn post hoc test }\end{array}$ \\
\hline
\end{tabular}

D Table 3 Physical characteristics of the non-LBP group and the LBP group across all subjects in the three weight categories.

\begin{tabular}{|c|c|c|c|c|c|c|c|c|}
\hline \multirow[b]{2}{*}{ Variables } & \multicolumn{2}{|l|}{ All subjects } & \multicolumn{2}{|c|}{ Lightweight } & \multicolumn{2}{|c|}{ Middleweight } & \multicolumn{2}{|c|}{ Heavyweight } \\
\hline & $\begin{array}{l}\text { Non-LBP } \\
(\mathrm{N}=43)\end{array}$ & $\begin{array}{l}\text { LBP } \\
(N=23)\end{array}$ & $\begin{array}{l}\text { Non-LBP } \\
(\mathrm{N}=9)\end{array}$ & $\begin{array}{l}\text { LBP } \\
(N=5)\end{array}$ & $\begin{array}{l}\text { Non-LBP } \\
(\mathrm{N}=20)\end{array}$ & $\begin{array}{l}\text { LBP } \\
(\mathrm{N}=9)\end{array}$ & $\begin{array}{l}\text { Non-LBP } \\
(\mathrm{N}=14)\end{array}$ & $\begin{array}{l}\text { LBP } \\
(\mathrm{N}=9)\end{array}$ \\
\hline Age (years) & $20.2 \pm 0.9$ & $20.2 \pm 0.9$ & $20.2 \pm 1.0$ & $20.0 \pm 1.0$ & $20.0 \pm 0.9$ & $19.9 \pm 0.6$ & $20.6 \pm 0.8$ & $20.6 \pm 1.0$ \\
\hline Height $(\mathrm{cm})$ & $172.6 \pm 5.2$ & $172.9 \pm 8.1$ & $168.3 \pm 3.3$ & $163.8 \pm 5.4$ & $172.1 \pm 4.5$ & $174.5 \pm 6.8$ & $176.0 \pm 4.9$ & $176.4 \pm 7.0$ \\
\hline Weight $(\mathrm{kg})$ & $83.2 \pm 15.1$ & $86.4 \pm 21.1$ & $67.5 \pm 3.7$ & $63.3 \pm 4.4$ & $78.8 \pm 5.0$ & $78.2 \pm 4.7$ & $99.4 \pm 14.3$ & $107.6 \pm 16.7$ \\
\hline BMI $\left(\mathrm{kg} / \mathrm{m}^{2}\right)$ & $27.8 \pm 4.1$ & $28.7 \pm 5.7$ & $23.8 \pm 1.0$ & $23.6 \pm 1.0$ & $26.6 \pm 1.9$ & $25.7 \pm 2.0$ & $32.0 \pm 4.0$ & $34.5 \pm 4.7$ \\
\hline $\begin{array}{l}\text { Judo history } \\
\text { (years) }\end{array}$ & $11.1 \pm 2.8$ & $10.6 \pm 3.5$ & $11.4 \pm 2.8$ & $9.0 \pm 4.0$ & $10.7 \pm 2.9$ & $10.0 \pm 2.6$ & $11.5 \pm 2.7$ & $12.0 \pm 3.8$ \\
\hline
\end{tabular}

Data are presented as mean \pm SD. LBP, low back pain. Lightweight, under $60 \mathrm{~kg}$ and $66 \mathrm{~kg}$ judokas. Middleweight, under $73 \mathrm{~kg}$ and $81 \mathrm{~kg}$ judokas.

Heavyweight, under 90, 100, and over $100 \mathrm{~kg}$ judokas.

We hypothesized that low TMS in judokas with LBP should be observed especially in those with heavy weight. At the beginning, we compared all judokas with and without LBP ( $\triangleright$ Table 4). There was no statistical difference between the non-LBP and LBP groups across all subjects. Since we suspected that the relation between LBP and TMS would be highlighted depending on weight category, we further divided judokas into three weight categories ( $>$ Table 5). As expected, in the heavyweight category, both the PTEX and PTRR at $60 \%$ of the LBP group were significantly lower than that of the nonLBP group $(P<0.05$, and $P<0.01$, respectively; > Table 5).

\section{Discussion}

The present study is the first trial to evaluate the relationship between judokas' TMS including rotator strength. We hypothesized that judokas with heavier body weight possess higher absolute
TMS, but lower relative TMS. As expected, relative extensor/flexor TMS showed higher values for those in a lighter weight category than those in a heavier weight category. On the contrary, the same tendency was not observed in the rotator TMS. Regarding the relations between TMS and LBP, significant associations between TMS and LBP were observed only in the heavyweight category, as expected.

\section{Low relative TMS of judokas in the heavyweight category was observed only in flexor/extensor strength}

The characteristics of weight-dependent TMS have not been previously reported. We found higher absolute TMS in the heavyweight category compared to those in the other two weight categories. On the other hand, we found that the relative TMS in the heavyweight category was lower in the flexor/extensor muscles. It was 
- Table 4 Comparison of peak torques of trunk muscles between subjects with and without LBP.

\begin{tabular}{|c|c|c|}
\hline Variables & $\begin{array}{l}\text { Non-LBP } \\
(\mathrm{N}=43)\end{array}$ & $\begin{array}{l}\text { LBP } \\
(N=23)\end{array}$ \\
\hline \multicolumn{3}{|c|}{ Extensor $(\mathrm{N} \cdot \mathrm{m} / \mathrm{kg})$} \\
\hline $60 \% \mathrm{~s}$ & $6.5 \pm 1.1$ & $6.1 \pm 0.8$ \\
\hline $90 \% \mathrm{~s}$ & $6.3 \pm 0.9$ & $6.0 \pm 0.7$ \\
\hline $120 \% \mathrm{~s}$ & $6.1 \pm 0.9$ & $5.8 \pm 0.7$ \\
\hline \multicolumn{3}{|c|}{ Flexor $(\mathrm{N} \cdot \mathrm{m} / \mathrm{kg})$} \\
\hline $60 \% \mathrm{~s}$ & $3.2 \pm 0.6$ & $3.1 \pm 0.7$ \\
\hline $90 \% \mathrm{~s}$ & $3.0 \pm 0.6$ & $2.9 \pm 0.6$ \\
\hline $120 \% \mathrm{~s}$ & $2.7 \pm 0.6$ & $2.5 \pm 0.6$ \\
\hline \multicolumn{3}{|c|}{ Extensor/Flexor ratio } \\
\hline $60 \% \mathrm{~s}$ & $2.1 \pm 0.5$ & $2.1 \pm 0.4$ \\
\hline $90 \% \mathrm{~s}$ & $2.2 \pm 0.6$ & $2.1 \pm 0.5$ \\
\hline $120 \% \mathrm{~s}$ & $2.3 \pm 0.6$ & $2.4 \pm 0.5$ \\
\hline \multicolumn{3}{|c|}{ Left-rotator $(\mathrm{N} \cdot \mathrm{m} / \mathrm{kg})$} \\
\hline $60 \% \mathrm{~s}$ & $2.2 \pm 0.3$ & $2.3 \pm 0.3$ \\
\hline $90 \% \mathrm{~s}$ & $2.2 \pm 0.3$ & $2.2 \pm 0.3$ \\
\hline $120 \% \mathrm{~s}$ & $2.1 \pm 0.3$ & $2.1 \pm 0.2$ \\
\hline \multicolumn{3}{|c|}{ Right-rotator $(\mathrm{N} \cdot \mathrm{m} / \mathrm{kg})$} \\
\hline $60 \% \mathrm{~s}$ & $2.4 \pm 0.3$ & $2.3 \pm 0.3$ \\
\hline $90 \% \mathrm{~s}$ & $2.2 \pm 0.3$ & $2.2 \pm 0.3$ \\
\hline $120 \% \mathrm{~s}$ & $2.2 \pm 0.3$ & $2.1 \pm 0.2$ \\
\hline \multicolumn{3}{|c|}{ Left-rotator/Right-rotator ratio } \\
\hline $60 \% \mathrm{~s}$ & $1.0 \pm 0.1$ & $1.0 \pm 0.1$ \\
\hline $90 \% \mathrm{~s}$ & $1.0 \pm 0.1$ & $1.0 \pm 0.1$ \\
\hline $120 \% \mathrm{~s}$ & $1.0 \pm 0.1$ & $1.0 \pm 0.1$ \\
\hline
\end{tabular}

reported during a judokas' handgrip strength test that those in a heavier weight category had a lower relative muscle strength than those in a lighter category [23], suggesting that relative muscular strength is low in heavyweight judokas. We now suspect that this is because their body weight may be too heavy for their TMS.

To our knowledge, this is the first study to investigate rotator TMS in judokas. In the first trial, we found that relative rotator TMS of the heavyweight category was not significantly different from that of the other two categories. The tendency is clearly different with flexor/extensor TMS strength. As mentioned in the introduction, the rotator strength of TMS is important in judo techniques [4]. Since high rotator TMS strength is demanded for judokas, relative rotator strength is independent of weight categories. The results also suggested that rotator strength should be evaluated and enhanced in judokas.

\section{Association of low relative extensor TMS with LBP in judokas in the heavyweight category}

Many previous studies involving ordinary people with LBP have shown significantly low strength of both the extensor and flexor muscles in the trunk, and that extensor strength has a greater impact for LBP than flexor strength [9-13]. However, other previous studies did not point out the same tendencies $[17,18]$. Moreover, it is also unclear whether flexor or extensor muscle strength contributes to the LBP of athletes, but these reflect the characteristics of their sport (e. g., extension strength for wrestling, trunk rotation strength for golfers) [19, 24]. In the present study, significance was confirmed only for PTEX and PTRR in the heavyweight category. As expected, a relationship between PREX/PTRR and LBP should exist because extensor and rotator strength are more needed in judokas, relatively speaking. However, as a result, significant relations of low TMS and LBP existed only in the heavyweight category; this suggests that the relationship between TMS and LBP varies among cases.

The relationship between low TMS and LBP was more apparent in judokas with heavier body weight. It is conceivable that the result was caused by higher load on the lumbar region caused by heavy body weight. This is consistent with our results showing that the absolute values of TMS were significantly larger in heavyweight judokas than those of the other two groups, although the ratio of TMS to body weight was lower in the heavyweight category than in other weight categories. The trunk muscle group has the role not only of agonist trunk movements, but it is also the dynamic stabilizer of lumbar region. LBP-related weakness of the trunk muscle group may be induced by high loads on the lumbar region brought about by sports activities [25]. Thus, the possibility of LBP occurring is higher in situations wherein there is the high load on the lumbar region caused by heavy body weight and the relative weakness of TMS.

Iwai et al. reported that low trunk extension muscle strength is associated with chronic LBP among wrestling athletes [19]. However, in terms of EX/FX ratio, extension muscle strength is higher than flexion strength, indicating that this represents the characteristics of their sport. There are a few studies that involved neither ordinary people nor athletes that found that the LBP of judokas has characteristics that are not associated with the abnormal agonist/ antagonist ratio in TMS regardless of the weight categories. It seems that judokas with LBP show overall lower TMS, and the strengths of trunk extensors and rotators, which are frequently employed in judo specifically, show much lower value.

We previously reported that LBP in middle- and heavyweight judokas almost always accompanies lumbar radiological abnormalities [8]. Therefore, we hypothesized that LBP in the lightweight category is more impacted by low TMS compared with other weight categories. However, the influence of low TMS is more apparent in the heavyweight category, as shown in this study. Although there was no significant difference, the average body weight of the heavyweight LBP group was heavier than that of the non-LBP group. Trunk muscle cross-sectional area (CSA) is related to LBP, and in the heavyweight category, the lack of muscle strength per body weight may indicate this result [26]. It is conceivable that we obtained contradictory results because we did not assess the differential diagnosis of LBP regarding lumbar radiological abnormalities. In the lightweight category, assignment based on the presence of lumbar radiological abnormalities, which is a major related factor of LBP, is needed because about half of all LBP cases are not accompanied by any lumbar radiological abnormalities. In the lightweight category specifically, there is a greater need to further investigate and remove the influence of lumbar radiological abnormalities. 
- Table 5 Comparison of peak torques of trunk muscles between subjects with and without LBP in the three weight categories.

\begin{tabular}{|c|c|c|c|c|c|c|}
\hline \multirow[b]{2}{*}{ Variables } & \multicolumn{2}{|c|}{ Lightweight } & \multicolumn{2}{|c|}{ Middleweight } & \multicolumn{2}{|c|}{ Heavyweight } \\
\hline & $\begin{array}{l}\text { Non-LBP } \\
(\mathrm{N}=9)\end{array}$ & $\begin{array}{l}\text { LBP } \\
(N=5)\end{array}$ & $\begin{array}{l}\text { Non-LBP } \\
(\mathrm{N}=\mathbf{2 0})\end{array}$ & $\begin{array}{l}\text { LBP } \\
(\mathrm{N}=9)\end{array}$ & $\begin{array}{l}\text { Non-LBP } \\
(\mathrm{N}=14)\end{array}$ & $\begin{array}{l}\text { LBP } \\
(N=9)\end{array}$ \\
\hline \multicolumn{7}{|c|}{ Extensor $(\mathrm{N} \cdot \mathrm{m} / \mathrm{kg})$} \\
\hline $60 \% \mathrm{~s}$ & $7.0 \pm 1.5$ & $6.3 \pm 0.5$ & $6.5 \pm 1.1$ & $6.4 \pm 0.8$ & $6.2 \pm 0.7$ & $5.6 \pm 0.6^{*}$ \\
\hline $90 \% \mathrm{~s}$ & $6.8 \pm 1.0$ & $6.2 \pm 0.8$ & $6.3 \pm 0.9$ & $6.3 \pm 0.5$ & $6.1 \pm 0.7$ & $5.5 \pm 0.5$ \\
\hline $120 \% \mathrm{~s}$ & $6.5 \pm 1.1$ & $6.1 \pm 0.7$ & $6.1 \pm 0.9$ & $6.1 \pm 0.5$ & $5.8 \pm 0.8$ & $5.3 \pm 0.8$ \\
\hline \multicolumn{7}{|c|}{ Flexor $(\mathrm{N} \cdot \mathrm{m} / \mathrm{kg})$} \\
\hline $60 \% \mathrm{~s}$ & $3.2 \pm 0.8$ & $3.4 \pm 0.7$ & $3.5 \pm 0.6$ & $3.4 \pm 0.7$ & $3.0 \pm 0.5$ & $2.6 \pm 0.6$ \\
\hline $90 \% \mathrm{~s}$ & $2.9 \pm 0.8$ & $3.3 \pm 0.4$ & $3.2 \pm 0.5$ & $3.2 \pm 0.6$ & $2.9 \pm 0.5$ & $2.5 \pm 0.6$ \\
\hline $120 \% \mathrm{~s}$ & $2.7 \pm 0.8$ & $2.9 \pm 0.3$ & $2.9 \pm 0.4$ & $2.8 \pm 0.5$ & $2.5 \pm 0.5$ & $2.1 \pm 0.5$ \\
\hline \multicolumn{7}{|c|}{ Extensor/Flexor ratio } \\
\hline $60 \% \mathrm{~s}$ & $2.3 \pm 0.7$ & $1.9 \pm 0.4$ & $1.9 \pm 0.5$ & $2.0 \pm 0.4$ & $2.2 \pm 0.4$ & $2.2 \pm 0.5$ \\
\hline $90 \% \mathrm{~s}$ & $2.5 \pm 0.8$ & $1.9 \pm 0.2$ & $2.0 \pm 0.5$ & $2.0 \pm 0.4$ & $2.2 \pm 0.5$ & $2.4 \pm 0.6$ \\
\hline $120 \% \mathrm{~s}$ & $2.6 \pm 0.9$ & $2.1 \pm 0.3$ & $2.1 \pm 0.4$ & $2.2 \pm 0.4$ & $2.4 \pm 0.5$ & $2.6 \pm 0.6$ \\
\hline \multicolumn{7}{|c|}{ Left-rotator $(\mathrm{N} \cdot \mathrm{m} / \mathrm{kg})$} \\
\hline $60 \% \mathrm{~s}$ & $2.2 \pm 0.2$ & $2.4 \pm 0.2$ & $2.2 \pm 0.3$ & $2.4 \pm 0.2$ & $2.2 \pm 0.2$ & $2.0 \pm 0.2$ \\
\hline $90 \% \mathrm{~s}$ & $2.3 \pm 0.2$ & $2.2 \pm 0.2$ & $2.2 \pm 0.3$ & $2.3 \pm 0.2$ & $2.2 \pm 0.3$ & $2.0 \pm 0.3$ \\
\hline $120 \% \mathrm{~s}$ & $2.2 \pm 0.2$ & $2.2 \pm 0.1$ & $2.1 \pm 0.3$ & $2.2 \pm 0.2$ & $2.1 \pm 0.4$ & $2.0 \pm 0.2$ \\
\hline \multicolumn{7}{|c|}{ Right-rotator $(\mathrm{N} \cdot \mathrm{m} / \mathrm{kg})$} \\
\hline $60 \% \mathrm{~s}$ & $2.3 \pm 0.2$ & $2.4 \pm 0.4$ & $2.4 \pm 0.3$ & $2.4 \pm 0.2$ & $2.4 \pm 0.3$ & $2.1 \pm 0.2^{* *}$ \\
\hline $90 \% \mathrm{~s}$ & $2.3 \pm 0.3$ & $2.3 \pm 0.3$ & $2.2 \pm 0.3$ & $2.2 \pm 0.2$ & $2.2 \pm 0.3$ & $2.0 \pm 0.3$ \\
\hline $120 \% \mathrm{~s}$ & $2.1 \pm 0.3$ & $2.2 \pm 0.2$ & $2.2 \pm 0.3$ & $2.1 \pm 0.2$ & $2.1 \pm 0.3$ & $1.9 \pm 0.2$ \\
\hline \multicolumn{7}{|c|}{ Left-rotator/Right-rotator ratio } \\
\hline $60 \% \mathrm{~s}$ & $1.0 \pm 0.1$ & $1.0 \pm 0.1$ & $1.0 \pm 0.1$ & $1.0 \pm 0.1$ & $1.0 \pm 0.1$ & $1.0 \pm 0.1$ \\
\hline $90 \% \mathrm{~s}$ & $1.0 \pm 0.1$ & $1.0 \pm 0.1$ & $1.0 \pm 0.1$ & $1.1 \pm 0.1$ & $1.0 \pm 0.1$ & $1.0 \pm 0.1$ \\
\hline $120 \% \mathrm{~s}$ & $1.0 \pm 0.1$ & $1.0 \pm 0.1$ & $1.0 \pm 0.1$ & $1.0 \pm 0.1$ & $1.0 \pm 0.1$ & $1.0 \pm 0.1$ \\
\hline
\end{tabular}

\section{Association of low relative rotator TMS with LBP in judokas in the heavyweight category}

As mentioned above, this is the first trial to investigate the relationships between rotator TMS and LBP in judokas. We first found that rotator TMS was the same among different weight categories. We also found that low rotator TMS was associated with LBP. There are a few studies that investigated the relationship between trunk rotator strength and LBP. These previous studies that involved ordinary people with LBP did not obtain the same results about the relationship between trunk rotator strength and LBP $[27,28]$. Other studies have also shown that endurance is more important to prevent LBP than trunk rotation strength in elite male golfers [24]. On the other hand, the present study could point out the relationship between significantly lower trunk rotator strength and LBP related to sports activities. We found that the relationship between the low strength of the trunk muscles and LBP is caused by intense sports activity, wherein demands vary per sport and/or a higher load on the lumbar region. This consideration was supported in the present study by confirming the relationship between low TMS and LBP only in the heavyweight category judokas.

Our colleagues Iwai et al. pointed out a strong relationship between LBP and low trunk extensor strength, which is particularly important for wrestlers [19]. Judo and wrestling have many similarities of sports specificities, thus trunk extensor strength is also important in judokas [1]. Also, torso rotation movement plays an important role in all situations of judo, particularly in throwing the opponent, defending throws made by the opponent, and releasing the opponent's hand grasping the sleeve of one's judo-specific uniform, called the judogi [1]. Moreover, Iwai et al. compared the lumbar muscle CSA and intervertebral disc degeneration (IDD) in combat sports (wrestler and judo), and found that the IDD group had small CSA [26]. This study indicated that the IDD group was asymmetrical. The left muscle group in the IDD group was significantly larger than right side. Similar results can be considered for this study, wherein significance was confirmed only with PTRR. It is considered that this result is caused by the differences of between right- and left-handed users, and/or the dominant direction of rotation.

In this study, there was no difference in the TMS of rotators among weight categories, but a significant difference was found when this was compared among patients with and without LBP. Many previous studies have found that the rotation of the trunk affects lumbar disk disease $[29,30]$. In our study, it was found that among athletes in the heavyweight category, many had LBP ac- 
companied by lumbar radiological abnormalities [8]. Low rotator muscle strength was confirmed only in the heavy weight judokas with LBP. In particular, the CSA of the external and internal oblique muscles of abdomen, which are the main muscles of trunk rotation, is relatively larger than that of other trunk muscle groups compared with wrestlers. It is possible that no differences were found in relative muscle strength among weight categories $[1,26]$.

\section{Limitations}

There are some limitations in this study. One of the most important points is a small sample size. Although a total of 66 judokas is a relatively small sample size, most of the participants in this study practiced judo for more than 10 years. Thus, the cohort of this study accurately represents the characteristics of judokas.

Another limitation of the present study is that LBP was not divided into subgroups diagnosed according to differences in pathology. There is a possibility that the role of TMS in the development of LBP varies among different pathologies. The diagnosis of LBP is done by abnormal lumbar radiological findings. We reported that almost all cases of LBP in the middle- and heavyweight categories were accompanied by at least one lumbar radiological abnormality [8]. Thus, in these two categories, it may be unnecessary to divide LBP into subgroups according the presence of abnormal lumbar radiological findings. However, about half of the LBP cases in the lightweight category were not accompanied by any lumbar radiological abnormalities [8]. Thus, for the lightweight category, it may be necessary to divide LBP into subgroups according to the presence of lumbar radiological abnormalities, and further investigation is needed remove the influence of these abnormalities on the results of the study. We speculated that the relationship between the low TMS and LBP is apparent after our investigation of the lightweight category.

\section{Conclusion}

The present study examined the characteristics of TMS in judokas across the weight categories and for those with and without LBP. The TMS of the extensor and flexor muscle groups was lower in the heavier weight category compared to other weight categories, but this did not hold true for the rotator muscle group. Furthermore, this study concluded that the TMS of heavyweight judokas with LBP is characterized by lower strength of the trunk extensor and rotator. The relatively high load on the lumbar region caused by heavier body weight is the probable cause for its relationship with LBP and low TMS, especially for rotator muscles.

\section{Acknowledgements}

The authors thank Yosuke Yamamoto, Professor (Nippon Sport Science University, Faculty of Sport Culture) for his valuable assistance.

\section{Conflict of Interest}

The authors declare that they have no conflict of interest.

\section{References}

[1] Iwai K, Okada T, Nakazato K et al. Sport-specific characteristics of trunk muscles in collegiate wrestlers and judokas. J Strength Cond Res 2008; 22: 350-358. doi:10.1519/JSC.0b013e3181635d25

[2] Henry T. Resistance training for judo: Functional strength training concepts and principles. Strength Cond J 2011; 33: 40-49

[3] Franchini E, Panissa VL, Julio UF. Physiological and performance responses to intermittent Uchi-komi in Judo. J Strength Cond Res 2013; 27: 1147-1155. doi:10.1519/JSC.0b013e3182606d27

[4] Franchini E, Brito CJ, Fukuda DH et al. The physiology of judo-specific training modalities. J Strength Cond Res 2014; 28: 1474-1481. doi:10.1519/JSC.0000000000000281

[5] Sward L, Eriksson B, Peterson L. Anthropometric characteristics, passive hip flexion, and spinal mobility in relation to back pain in athletes. Spine (Phila Pa 1976) 1990; 15: 376-382. doi:10.1097/00007632-199005000-00007

[6] Sward L, Hellstrom M, Jacobsson B et al. Back pain and radiologic changes in the thoraco-lumbar spine of athletes. Spine (Phila Pa 1976) 1990; 15: 124-129. doi:10.1097/00007632-199002000-00015

[7] Yamaji O, Imai N, Arima T. Lumbar disorders of the judo players. Tokay J Sports. Med Sci 1992; 4: 46-51

[8] Okada T, Nakazato K, Iwai K et al. Body mass, nonspecific low back pain, and anatomical changes in the lumbar spine in judo athletes. J Orthop Sports Phys Ther 2007; 37: 688-693. doi:10.2519/ jospt.2007.2505

[9] Handa N, Yamamoto H, Tani T et al. The effect of trunk muscle exercises in patients over 40 years of age with chronic low back pain. Orthop Sci 2000; 5: 210-216. doi:10.1007/s007760050153

[10] Hupli M, Hurri H, Luoto $S$ et al. Isokinetic performance capacity of trunk muscles. Part I: The effect of repetition on measurement of isokinetic performance capacity of trunk muscles among healthy controls and two different groups of low-back pain patients. Scand J Rehabil Med 1996; 28: 201-206

[11] Mayer TG, Smith SS, Keeley J et al. Quantification of lumbar function. Part 2: Sagittal plane trunk strength in chronic low-back pain patients. Spine (Phila Pa 1976) 1985; 10: 765-772

[12] Shirado O, Ito T, Kaneda K et al. Concentric and eccentric strength of trunk muscles: influence of test postures on strength and characteristics of patients with chronic low-back pain. Arch Phys Med Rehabil 1995; 76: 604-611. doi:10.1016/s0003-9993(95)80628-8

[13] Takemasa R, Yamamoto H, Tani T. Trunk muscle strength in and effect of trunk muscle exercises for patients with chronic low back pain. The differences in patients with and without organic lumbar lesions. Spine (Phila Pa 1976) 1995; 20: 2522-2530. doi:10.1097/00007632199512000-00012

[14] Flory PD, Rivenburgh DW, Stinson JT. Isokinetic back testing in the athlete. Clin Sports Med 1993; 12: 529-546

[15] Kankaanpaa M, Taimela S, Laaksonen D et al. Back and hip extensor fatigability in chronic low back pain patients and controls. Arch Phys Med Rehabil 1998; 79: 412-417. doi:10.1016/s0003-9993(98)901423

[16] Rodriquez AA, Bilkey W], Agre JC. Therapeutic exercise in chronic neck and back pain. Arch Phys Med Rehabil 1992; 73: 870-875

[17] Balague F, Damidot P, Nordin M et al. Cross-sectional study of the isokinetic muscle trunk strength among school children. Spine (Phila Pa 1976) 1993; 18: 1199-1205. doi:10.1097/00007632-19930700000013

[18] Shirado O, Kaneda K, Ito T. Trunk-muscle strength during concentric and eccentric contraction: a comparison between healthy subjects and patients with chronic low-back pain. J Spinal Disord 1992; 5: 175-182. doi:10.1097/00002517-199206000-00005 
[19] Iwai K, Nakazato K, Irie K et al. Trunk muscle strength and disability level of low back pain in collegiate wrestlers. Med Sci Sports Exerc 2004; 36: 1296-1300. doi:10.1249/01.mss.0000135791.27929.c1

[20] Moreno Catala M, Schroll A, Laube G et al. Muscle strength and neuromuscular control in low-back pain: Elite athletes versus general population. Front Neurosci 2018; 12: 436. doi:10.3389/ fnins.2018.00436

[21] Harriss D, MacSween A, Atkinson G. Ethical standards in sport and exercise science research: 2020 update. Int J Sports Med 2019; 40: 813-817

[22] Kuroki T, Tajima N. The prevention effect of therapeutic exercise on low back pain in athletes. J Phys Med 1996; 7: 92-96

[23] Franchini E, Schwartz ], Takito MY. Maximal isometric handgrip strength: comparison between weight categories and classificatory table for adult judo athletes. J Exerc Rehabil 2018; 14: 968-973. doi:10.12965/jer.1836396.198

[24] Lindsay DM, Horton JF. Trunk rotation strength and endurance in healthy normals and elite male golfers with and without low back pain. N Am J Sports Phys Ther 2006; 1: 80
[25] Danneels L, Cools A, Vanderstraeten G et al. The effects of three different training modalities on the cross-sectional area of the paravertebral muscles. Scand J Med Sci Sports 2001; 11: 335-341

[26] Iwai K, Koyama K, Okada T et al. Asymmetrical and smaller size of trunk muscles in combat sports athletes with lumbar intervertebral disc degeneration. Springerplus 2016; 5: 1474. doi:10.1186/ s40064-016-3155-8

[27] Mayer TG, Smith SS, Kondraske G et al. Quantification of lumbar function. Part 3: Preliminary data on isokinetic torso rotation testing with myoelectric spectral analysis in normal and low-back pain subjects. Spine (Phila Pa 1976) 1985; 10: 912-920

[28] Lee JH, Hoshino Y, Nakamura $\mathrm{K}$ et al. Trunk muscle weakness as a risk factor for low back pain. A 5-year prospective study. Spine (Phila Pa 1976) 1999; 24: 54-57. doi:10.1097/00007632-199901010-00013

[29] Gillies A, Dorgo S. Preventing lumbar injuries in rotational striking athletes. Strength Cond J 2013; 35: 55-62

[30] Hangai M, Kaneoka K, Hinotsu S et al. Lumbar intervertebral disk degeneration in athletes. Am J Sports Med 2009; 37: 149-155. doi:10.1177/0363546508323252 